\title{
Establishment of the Computer-Aided Command and Control System for Emergency and Crisis Management
}

\author{
Chuanjie Yang, Jianguo Chen, Guofeng $\mathrm{Su}^{+}$, Jianping Zhang \\ Institute of Public Safety Research, Department of Engineering Physics, Tsinghua University
}

\begin{abstract}
China is one of the top-ranked countries for numbers of disasters all over the world. The new drivers of change such as globalization, technological development, environmental changes, economic uncertainty and the changing roles of individuals in society make the situation even worse. Addressing these issues, a security-guaranteed society should be established to promote the public security and safety. In this paper, we established the major core capabilities covering the prevention and preparedness, monitoring and early warning, emergency disposal and rescue, and recovery and reconstruction during the emergency and crisis management. ECMS was designed to support the incident manager to deliver the major core capabilities which are assigned into prevention, protection, mitigation, response, and recovery five mission areas. With ECMS, the whole community can work together to conduct the emergency and crisis management through effective information utilization, efficient data exchange, and the overall performance of the whole disaster process to save lives and protect property and the environment.
\end{abstract}

Keywords: Emergency and crisis management System (ECMS), emergency operation centre, command and control, standard operation procedure (SOP), public safety and security

\section{Introduction}

Although science and technology have a tremendous development in recent years, disaster management is still a worldwide problem, especially for large-scale disasters that affect many countries (e.g. the 2004 Indian Ocean earthquake and tsunami), highly population concentrated areas where most frequently hit by natural disasters (e.g. China, the United States, the Philippines, Indonesia and India) and multi-hazards (e.g. Tohoku Earthquake and landslides). The most recent international disaster database[1] found that, in 2015, a total of over 346 reported disasters resulted in 22,773 people dead, 98.6 million people affected, and US\$66.5 billion economic damage worldwide. The new trends and challenges such as high population growth, urbanization, and global climate change drive up the frequency of disasters, which make the situation even worse.

In order to reduce the adverse effects caused by disasters, the United Nations established Sendai Framework for Disaster Risk Reduction 2015-2030 in 2015. The Sendai Framework defined the principles and responsibilities in reducing disaster risk at local, national, regional and global levels by countries and other relevant stakeholders[2]. Up to now, many countries have enhanced their capacities in disaster risk management, including improving the international mechanisms for strategic advice, coordination and partnership development for disaster risk reduction, establishing the Global Platform or regional platforms for disaster risk reduction, as well as other relevant international and regional forums for cooperation. The World Health Organization also established a Framework for a Public Health Emergency Operations Centre in 2015[3] to define the principles and responsibilities for practitioners of public health, health policy makers and authorities and agencies responsible for managing emergencies, incidents, or events where the health of

\footnotetext{
+ Corresponding author. Tel.: +86-010-62792860; fax: + 86-010-62792860

E-mail address: sugf@tsinghua.edu.cn
} 
populations is at risk. The document also provides high-level methodical guidance for designing, developing, and strengthening of public health emergency operations centres.

China is one of the top-ranked countries for numbers of disasters all over the world[4]. Centre for research on the epidemiology of disasters reported that China is the second highest numbers of natural disasters in 2015, the first highest numbers of climate-related vs. geophysical disasters during 1994-2003, and the third highest economic losses from natural disasters in absolute value of 453 US\$ during 19942003[5]. To deal with the frequent occurrences of disasters, the Chinese government attaches great importance to disaster management. It is noticeable that China has made major commitments to reduce disaster losses by acting on the priorities of the Hyogo Framework for Action which has succeeded in keeping economic losses within a target of $1.5 \%$ of GDP[5]. Besides, the government has taken the emergency and crisis management as an essential element for Nation's security and must be firmly embedded in and linked to the goal of national power strategy.

The core functions of disaster management are to make the emergency managers and the private sector to work together to prevent, protect against, respond to, recover from, and mitigate the effects of incidents, regardless of cause, size, location, or complexity[6]. In china, the incident management priorities include saving lives, stabilizing the incident, and protecting property and the environment. The objective of this paper is to design a computer-aided command and control system to help the whole community including individuals, communities, the private and non-profit sectors, faith-based organizations, and governments to work together during all the processes - prevention, protection, mitigation, response, and recovery.

\section{Core Capabilities of Emergency and Crisis Management}

In China, there are four major core capabilities, prevention and preparedness, monitoring and early warning, emergency disposal and rescue, and recovery and reconstruction during the emergency and crisis management. The above four core capabilities are assigned into the following five mission areas: prevention, protection, mitigation, response, and recovery (see Table 1).

Table I. Core capabilities by mission area

\begin{tabular}{|c|c|c|c|c|}
\hline Prevention & Protection & Mitigation & Response & Recovery \\
\hline \multicolumn{5}{|c|}{ Planning } \\
\hline \multicolumn{5}{|c|}{ Information acquiring and sharing } \\
\hline \multicolumn{5}{|c|}{ Situational awareness } \\
\hline \multicolumn{5}{|c|}{ Disaster monitoring, warning, forecasting and disseminating } \\
\hline \multicolumn{5}{|c|}{ Communication and coordination } \\
\hline \multicolumn{5}{|c|}{ Conventional and unknown risk identification and assessment } \\
\hline \multirow{2}{*}{\multicolumn{2}{|c|}{ Interdiction and disruption }} & \multirow{2}{*}{ Community resilience } & \multicolumn{2}{|c|}{\begin{tabular}{|l|} 
Infrastructure Systems \\
\end{tabular}} \\
\hline & & & Critical Transportation & Fconomic recoyery \\
\hline \multirow{8}{*}{$\begin{array}{l}\text { Forensics and } \\
\text { attribution }\end{array}$} & Cybersecurity & \multirow{8}{*}{$\begin{array}{l}\text { Threats and hazards } \\
\text { identification }\end{array}$} & People and & 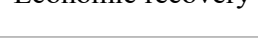 \\
\hline & \multirow{3}{*}{$\begin{array}{c}\text { Identity verification in } \\
\text { access control system } \\
\text { Protection of } \\
\text { important targets } \\
\end{array}$} & & environment safety & \multirow{3}{*}{$\begin{array}{c}\text { Health and } \\
\text { social services }\end{array}$} \\
\hline & & & Stabilizing the incident & \\
\hline & & & $\begin{array}{c}\text { Logistics and supply } \\
\text { chain management }\end{array}$ & \\
\hline & $\begin{array}{l}\text { Risk management for } \\
\text { protection programs }\end{array}$ & & Command and control & \multirow[t]{2}{*}{ Housing } \\
\hline & and activities & & On-site emergency & \\
\hline & \multirow{2}{*}{$\begin{array}{c}\text { Supply chain integrity } \\
\text { and security }\end{array}$} & & disposal & \multirow{2}{*}{$\begin{array}{c}\text { Natural and cultural } \\
\text { resources }\end{array}$} \\
\hline & & & Emergency action plan & \\
\hline
\end{tabular}

\section{Overall Design of Emergency and Crisis Management System (ECMS)}

Aiming at the emergency management, such as the natural disasters, accident disasters, criminal events and other emergencies, we designed the computed-aided command and control system maned emergency and crisis management system (ECMS) to deliver the core capabilities as mentioned in table 1 . The overall design of ECMS is presented in figure 1. The ECMS, composed by core business section and auxiliary support section, is a well-designed information system with effective information utilization, efficient data exchange, and the overall performance of the whole disaster process (Prevention, protection, mitigation, response and recovery). Besides, ECMS helps all levels (local, reginal, and national) of government, 
nongovernmental organizations (NGO), and the private sector to work together to conduct the emergency and crisis management.

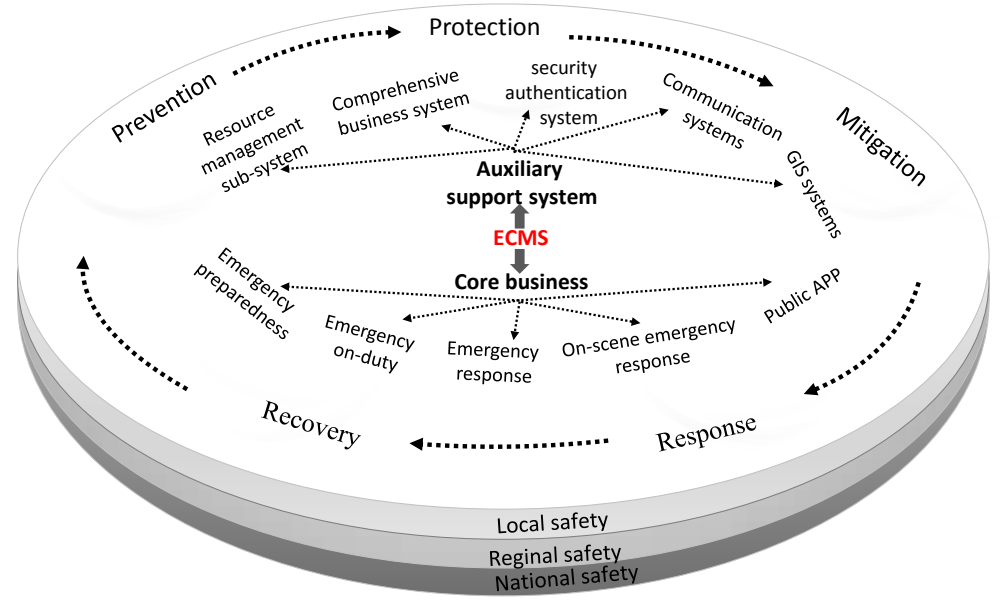

Fig. 1: The overall design of ECMS

\section{Establishment of Emergency and Crisis Management System}

The function design of ECMS focused on-duty and the emergency response modules is depicted in figure 2. As shown in figure 2, the core function of ECMS are as follows:

(1) Basic data collection: emergency resources information such as resource location and status; protection target information such as hospital; hazards information such as nuclear power plant; organization and contacts.

(2) On-duty: multi-channel incident reporting, such as fixed voice call, mobile call, short message, intelligent video analysis, front-end sensors, and APP for citizens' phones; information dissemination provides the effective communication between public and emergency mangers to avoid panic due to information gap; auxiliary information realize the established unified terminology, standard, and laws and regulations to support the interoperable framework.

(3) Incident management: incident list can help the emergency manager have a quick overview of all incident information, as well as quickly select, edit, merge, correlation and transferred incidents.

(4) Emergency disposal: EOC management means monitoring the operation status of EOC, including infrastructure operating status, personnel status and business operation status; IAP (incident action plan) represents concise, coherent means of capturing and communicating overall incident objectives, tactics, and assignments for operational and support activities in the field to deal with all problems during the incidents. SOP and case assisting can help the decision makers quickly make IAP based one the standard operation procedure or the previous successful cases; public information interaction means an effective communication between emergency managers and the public through a variety of traditional and social media outlets, public APP, or public communication channels of government departments; trajectory tracking can help emergency managers know the resources and personnel status on the scene, as well as task execution status.

(5) On-site terminal: the on-site terminal can help the emergency response personnel keep in touch with EOC through reporting and receiving information function, task receiving and feedback function and contacts function.

(6) Public APP: the public APP can help the public keep in touch with emergency response personnel and EOC through information reporting, information reception and contact us functions; information sharing can realize the communication between the public and the emergency managers, and between the public and the public.

(7) Statistical analysis: the statistical analysis focus on the reporting and receiving information statistics, the emergency disposal information statistics, and the historical incident information statistics. 


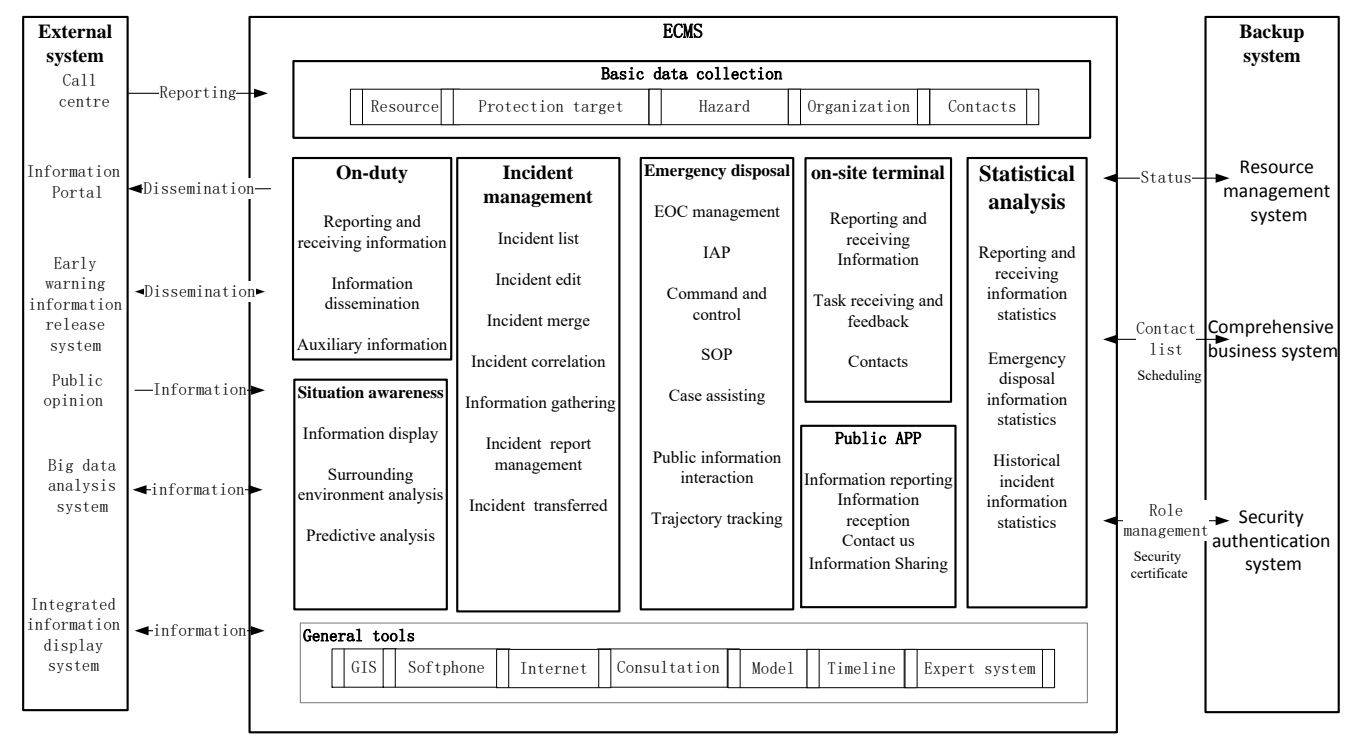

Fig. 2: The function design of ECMS

According to ECMS core functions, we designed emergency the on-duty business and the emergency response business. The workflow of those modules in ECMS are summarized in figures 3 and 4, for emergency on-duty business module and emergency response business module, respectively.

As shown in figure 3, if there is an emergency or crisis occurred, the lower authority command center, such as 911, reports the incident information to on-duty officer in the command center. The on-duty officer make a situational awareness about the incident type, level, damage, the potential risks. Then the on-duty officer or on-duty officer leader make a decision about the incident, for example, reporting the incident to the higher authority command center if the incident beyond the corresponding level, turning down the incident to the lower authority command center if the incident lower the corresponding level, and making a fast response to the incident if the incident equal the corresponding level.

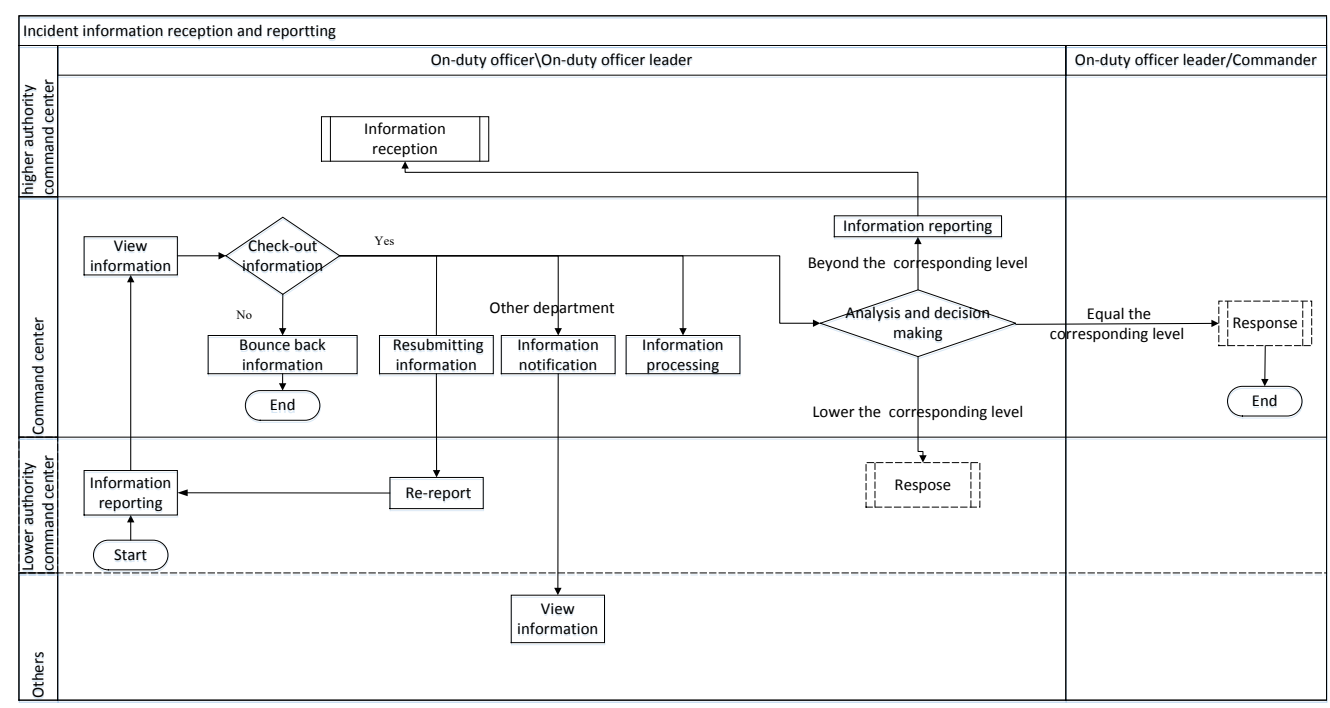

Fig. 3: The workflow of emergency on-duty business module

When the incident is equal to the corresponding level, the on-duty officer leader acts as the first responder to deal with the incident, as shown in figure 4. There are two procedures for incident response. The first one is fast response or the first response, no IAP is needed. Under this conditions, the on-duty officer leader directly make task assignment to response the incident until the incident is closed. However, sometimes, the incident is in large-scale, or becoming large or complex, local EOC should be activated. Under this conditions, the commander should initiate the incident action planning process. Generally, the IAP is proposed by time driven with 12 to 24 hours or by incident driven when the incident undergo huge situational changes. 


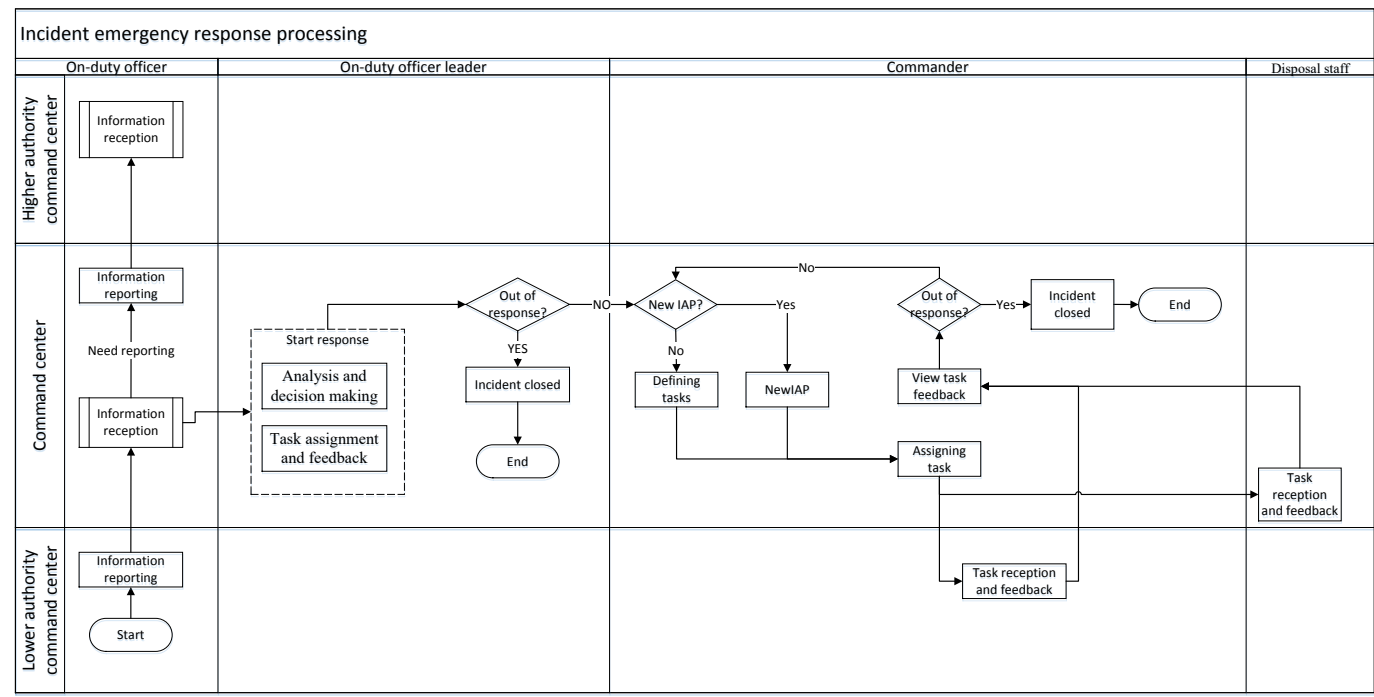

Fig. 4: The workflow of emergency response business module

\section{Conclusion}

ECMS is dedicated to government emergency agencies to provide emergency on-duty at ordinary times and fast and effective response to the incident with core business, including the emergency preparedness, emergency on-duty, emergency response, on-scene emergency response and public APP. Through the ECMS, the following capabilities can be achieved: (1) Dynamic management ability, which is building the overall goals and strategies, and the tactical plans based on the incident situation; (2) Situation assessment ability. Based on the big data analysis system and multi-channel terminal devices, the emergency manager can easily obtain the damage information, hospital information, shelter information, and resource information. All those information can improve the ability of field situation assessment; (3) command and control ability. ECMS can easily integrates seamlessly with mobile terminal to deploy mobile dispatch capabilities on laptops, smartphones, and tablets to help field personnel get fast and easy access to critical applications and information. Through the standard operating procedures (SOP) and cases, the emergency managers can achieve more efficient operations; and (4) realize the whole community to work together. The ECMS brings the whole community to work together through the public APP to prevent, protect against, mitigate, respond to, and recover from the threats and hazards caused by disasters.

\section{Acknowledgements}

This work was supported by National Key Technology Research and Development Program of the Ministry of Science and Technology of China (Grant No.: 2015BAK10B04).

\section{References}

[1] EM-DAT. 2016. The OFDA/CRED - International Disaster Database Université www.emdat.be catholique de Louvain Brussels - Belgium

[2] United Nations. 2015. Sendai Framework for Disaster Risk Reduction 2015-2030. http://www.preventionweb.net/drr-framework/sendai-framework

[3] World Health Organization. Framework for a Public Health Emergency Operations Centre www.who.int/about/licensing/copyright_form/en/index.html

[4] Davis, I., 2015. Disaster Risk Management in Asia and the Pacific. First published 2015 by Routledge 2 Park Square, Milton Park, Abingdon, Oxon OX14 4RN and by Routledge, 711 Third Avenue, New York, NY 10017

[5] CRED, 2015. The human cost of natural disasters, 2015, a global perspective. http://reliefweb.int/report/world/human-cost-natural-disasters-2015-global-perspective

[6] FEMA, 2016. Working draft national incident management system refresh review package. https://www.fema.gov/national-incident-management-system/national-engagement 